\title{
A revision of the Aphaenogaster phalangium complex (Hymenoptera: Formicidae: Myrmicinae)
}

\author{
JOHN T. LONGINO* \& STEFAN COVER ** \\ * The Evergreen State College, Olympia, Washington 98505, USA ${ }^{1}$; longinoj@evergreen.edu \\ ** The Museum of Comparative Zoology, Harvard, MA 02138, USA \\ 1. To whom correspondence should be addressed.
}

\begin{abstract}
The Aphaenogaster phalangium complex is a lineage of rainforest ants endemic to Central America. The complex is revised and interpreted as two parapatric species, A. phalangium and A. araneoides, with extensive geographic variation. Character variation is discordant within species, but in some cases appears to vary in parallel between the two species, such that both species vary the same way in montane versus lowland sites. Aphaenogaster inermis Forel 1899, A. nitidiventris Forel 1912, and A. canalis Enzmann 1947 are synonymized under A. phalangium Emery 1890; and A. brevicollis Forel 1899 is synonymized under A. araneoides Emery 1890. The complex lacks winged queens and instead has ergatoid queens with enlarged postpetiole and gaster.
\end{abstract}

Key words: Aphaenogaster phalangium, Aphaenogaster araneoides, Formicidae, geographic variation

\section{Introduction}

Forested habitats of Central America are home to ants of the Aphaenogaster phalangium complex. Within the context of the New World Aphaenogaster fauna, the workers of the phalangium complex are uniquely identified by a combination of head and propodeum characters. The portion of the head posterior to the eyes is drawn out and tapers to a strongly constricted neck, beyond which the head flares out into a pronounced collar. The propodeum lacks spines, although it may be weakly tuberculate. The workers are large, with long spindly legs. They are a common element of many lowland rainforest sites, where solitary foragers are common on the forest floor. They are timid ants that run from any threat, and they are decidedly comical with their large heads on implausibly narrow necks. The nests are in small chambers in the ground, and colonies maintain multiple empty nests, moving among them (McGlynn et al. 2002, 2003). 
At a global level the definition of the genus Aphaenogaster is problematic, and early definitions of subgenera (Emery 1915) have been relegated to synonymy (Bolton 1982). The members of the phalangium complex have been moved from taxon to taxon, spending time in Stenamma, Aphaenogaster subgenus Ischnomyrmex (now a synonym of Pheidole) and Aphaenogaster subgenus Deromyrma (now a synonym of Aphaenogaster). The relationship of the phalangium complex to other Aphaenogaster has not been explored, but as mentioned above, the complex forms a strongly differentiated and unmistakable lineage in Central America.

Emery (1890) named the first two species, A. phalangium and A. araneoides, both from Costa Rica. Forel subsequently described $A$. phalangium brevicollis from Panama, $A$. araneoides inermis from Costa Rica and Panama, and A. araneoides nitidiventris from Costa Rica. Enzmann described A. araneoides canalis from Panama. These descriptions date from the era of typological ant naming and there has never been a synthetic taxonomic work that differentiates all the forms or addresses geographic variation. Additional collections now available reveal complex character variation that makes early taxon definitions untenable. Here we analyze character variation and propose new hypotheses of species boundaries that propose parallel clinal variation in two species.

\section{Character variation}

The material on which we base our observations is comprised of multiple collections from a few well-sampled locations and single collections from numerous other locations. The localities for which we have multiple collections are La Selva Biological Station in the Atlantic lowlands of Costa Rica, the Peñas Blancas Valley on the Atlantic slope of the Cordillera de Tilarán, Monteverde (only 10km distant from the Peñas Blancas site but on the Pacific slope), Corcovado National Park in the southern Pacific lowlands of Costa Rica, and Barro Colorado Island in central Panama. These collections reveal that intrapopulational variation in obvious morphological features is always very low, but that dramatic character shifts can occur over short distances.

The most discrete character set, and the one on which we base our definitions of species, involves pilosity on the femora of workers (Fig. 1). Aphaenogaster phalangium is a "pilose" form, and A. araneoides is a "non-pilose" form. Aphaenogaster phalangium has femora with short stiff erect setae that cover all surfaces. In contrast, A. araneoides has the dorsal and lateral faces of the femora with only very fine, fully appressed setae, and erect setae are confined to the ventral surface. In most cases there is also a pilosity difference on the mesepisternum. Aphaenogaster phalangium usually has ten or more erect setae scattered along the full length of the mesepisternum. In contrast, A. araneoides is usually devoid of erect setae on the mesepisternum, or with at most one or two at the ventral border. Rarely (see A. brevicollis) there is a row of about five setae along the posterior border. The two species exhibit a largely parapatric distribution with a narrow zone of sympatry 
(Fig. 2). Aphaenogaster phalangium occurs in a narrow strip along the mid-elevation Pacific slope of Costa Rica's cordilleras, fanning out into the wet Pacific lowlands of southwestern Costa Rica, and extending into Panama as far as Barro Colorado Island and the Darien. Aphaenogaster areneoides is the Atlantic slope counterpart, also occurring in the mid-elevation cordilleras of Costa Rica, but fanning out into the Atlantic lowlands, with isolated records from El Salvador and Honduras.

In the zone of sympatry collections are sparse, but one locality shows evidence of discrete sympatric species. In the Monteverde area of the Cordillera de Tilarán, one colony of A. phalangium and eight separate worker samples of $A$. araneoides have been collected. Elsewhere, collections of both species have been taken from closely approximated localities (Fig. 2). For example, in the Cordillera de Guanacaste, an A. phalangium worker was collected from Cerro Cacao, at $1500 \mathrm{~m}$, while an A. araneoides worker was collected from Maritza Biological Station, at $600 \mathrm{~m}$ elevation and only $6 \mathrm{~km}$ from Cerro Cacao.

A character that we interpret as being intraspecifically variable is the sculpture on the fourth abdominal tergite. This tergite may be completely smooth and shining or variably matte and dull. For A. phalangium, specimens from the montane sites in the cordilleras of Guanacaste, Tilarán, and Talamanca have the tergite smooth and shining or matte anteriorly grading to smooth posteriorly. Specimens from the lowlands, including the southern Pacific lowlands of Costa Rica and the population on Barro Colorado Island, have the tergite completely matte. For A. araneoides, the pattern is more or less the same. Specimens from the Costa Rican cordilleras and the one collection from Honduras tend to have the tergite shiny; specimens from the Atlantic lowlands and the collection from El Salvador have the tergite matte.

The shape of the neck, although difficult to quantify, shows subtle variation (Fig. 3). In lateral view, the neck may be (1) very strongly constricted and with a strongly developed dorsal flange, or (2) relatively weakly constricted with a reduced dorsal flange. In the first instance the profile of the head looks like a bottle or flask with rounded shoulders and a separate neck; in the second it looks like a flask that tapers to the opening. Aphaenogaster phalangium always has the strongly constricted neck. Specimens of A. araneoides from the Atlantic lowlands of Costa Rica up to the Peñas Blancas Valley show the weakly constricted neck, while those from Monteverde and elsewhere in the central cordilleras have the strongly constricted neck of $A$. phalangium. Strong character variation occurs over small spatial scales. In the Peñas Blancas Valley workers have the same neck shape as workers from La Selva and the slopes of the Cordillera Volcanica Central but the shiny abdominal tergites similar to material of $A$. araneoides from Monteverde. In Monteverde, only $10 \mathrm{~km}$ from Peñas Blancas, not only are the abdominal tergites shiny, the neck shape is very different too, matching both $A$. araneoides and A. phalangium material from further north.

The propodeum may have short posterodorsal tubercles (where the propodeal spines would be in other Aphaenogaster), or these may be completely lacking. Propodeal tubercles occur on specimens from the Atlantic slope of the Cordillera Volcanica Central south 
to the Rio Sixaola on the border between Costa Rica and Panama. Specimens from north and south (the Peñas Blancas Valley and Changuinola, Panama, respectively) lack the tubercles.

The low number of males in collections reduces knowledge of male character variation, but some observations are warranted. We have examined males of A. phalangium from Corcovado, Quepos (a site on the Pacific coast just north of Corcovado), and Barro Colorado Island, and males of A. araneoides from La Selva, two other Atlantic lowland sites south of La Selva, and Monteverde. The leg pilosity character does not differentiate the species, because femora of both species have appressed setae on the dorsal and lateral faces (although the femoral pilosity of $A$. phalangium males is not as strongly appressed). The males often retain the pilosity differences on the mesepisternum. The A. phalangium males have sparse setae scattered over the katepisternum and often on the anepisternum as well. These setae vary from being thickened and easily seen to very fine, delicate, and difficult to see. In contrast, the mesepisternum of A. araneoides males is usually entirely or almost entirely devoid of setae, with at most one or two at the ventral border. However, the males of Forel's A. brevicollis (see below) have setae on the katepisternum, yet the worker leg pilosity places them in A. araneoides. The fourth abdominal tergite of all males we have examined has been entirely smooth and shiny, or with at most a small amount of shagreening near the postpetiolar insertion. The males vary intraspecifically in the size of the compound eyes (Fig. 4), and like some worker characters eye size does not seem to correlate with species boundaries. Male eyes are small in A. araneoides from Monteverde, A. phalangium from Corcovado, and A. araneoides from Changuinola. Male eyes are large and bulging in A. phalangium from Barro Colorado Island and A. araneoides from Bataan and La Selva, both Costa Rican Atlantic lowland sites. The shift from small to large eyes across the Rio Sixaola appears to correlate with the shift from the non-tuberculate to tuberculate condition in workers.

\section{Queens}

McGlynn et al. (2002) found that colonies of A. araneoides at La Selva Biological Station never contained alate queens, but instead contained one or two ergatoid queens. In our examination of museum material we have never seen an alate queen, and four nest series (two of A. araneoides collected by E. O. Wilson at La Selva, one of A. phalangium collected by G. C. Wheeler on Barro Colorado Island, and one of A. phalangium collected by Longino from Monteverde) contain single ergatoid queens. In each of these collections one adult female has an allometrically enlarged postpetiole and fourth gastral tergite (Fig. 5). Also the metanotal groove is more deeply impressed relative to workers. There are no traces of wing scars or the sclerites associated with wings. The La Selva individuals have an ocellar triangle with distinct ocelli. The Barro Colorado individual lacks ocelli but there is a small depression where the median ocellus would be. The Monteverde specimen has no trace of ocellus or depression. 

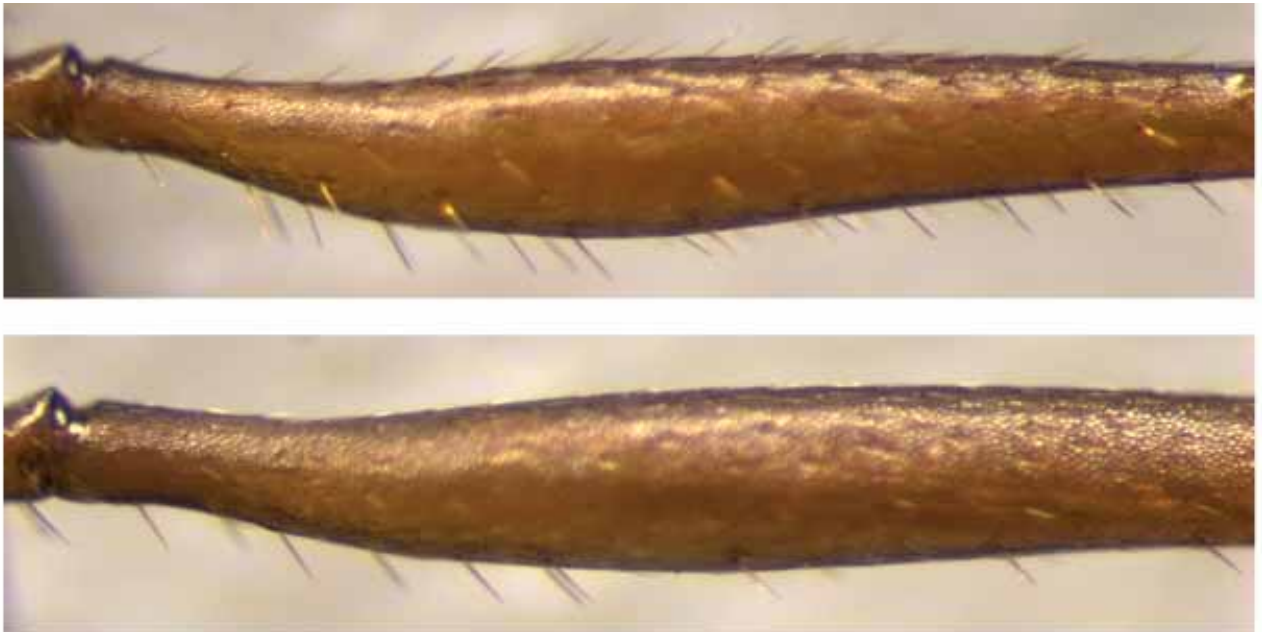

FIGURE 1. Anterior face of worker posterior femur, showing contrasting pilosity of Aphaenogaster phalangium and A. araneoides. Aphaenogaster phalangium has erect setae on all faces. Aphaenogaster araneoides has erect setae on ventral surface only.

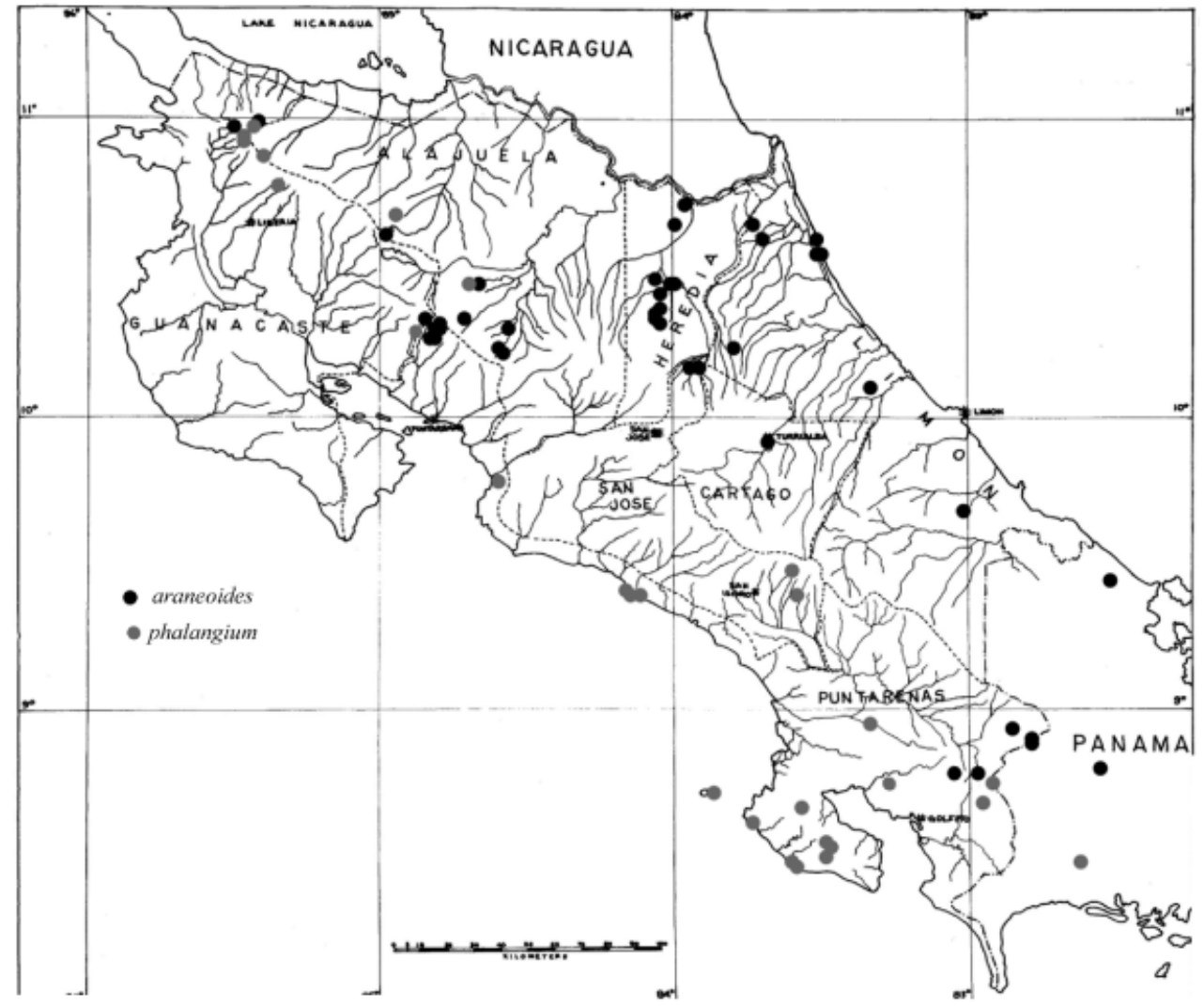

FIGURE 2. Distribution map of Aphaenogaster phalangium and A. araneoides. Specimens examined are the combined holdings of the Museum of Comparative Zoology at Harvard, the Instituto Nacional de Biodiversidad (INBio) in Costa Rica, and the private collection of the senior author. Detailed specimen data are available at the Ants of Costa Rica website (www.evergreen.edu/ants). Not included on the map are specimens from Honduras, El Salvador, and central Panama. 


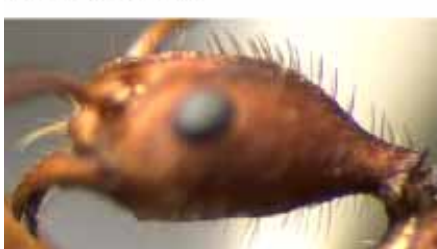

$\mathrm{BCl}$

araneoides

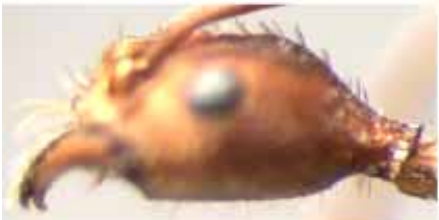

El Salvador

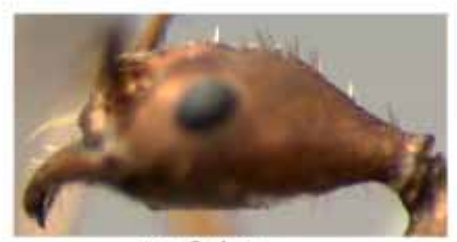

La Selva

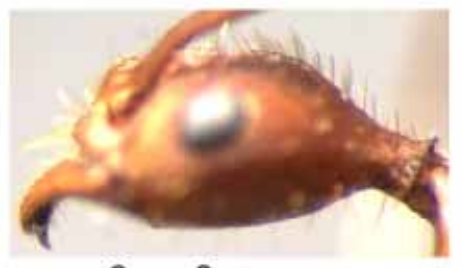

Cerro Cacao

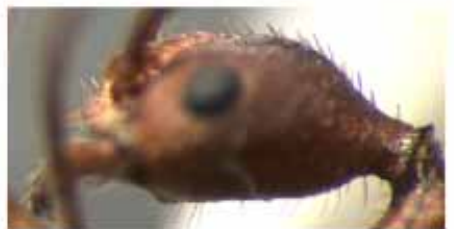

Honduras

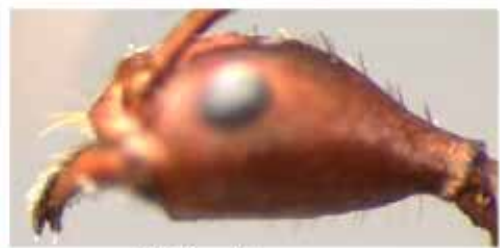

Peñas Blancas

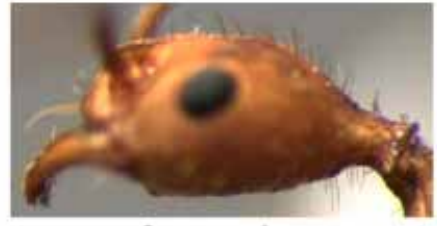

Corcovado

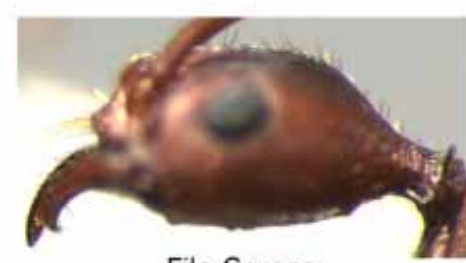

Fila Cruces

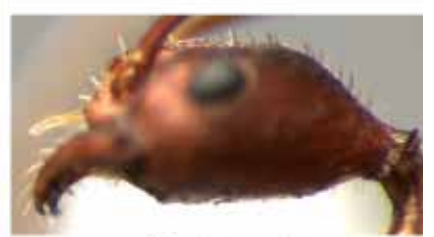

Monteverde

$1 \mathrm{~mm}$

FIGURE 3. Lateral view of worker head, Aphaenogaster phalangium complex.

\section{Key to species (workers)}

1 Dorsal and lateral faces of femora with abundant erect setae; mesepisternum with ten or more erect setae scattered over surface.

A. phalangium

- Dorsal and usually lateral faces of femora with fully appressed setae; mesepisternum usually completely lacking erect setae, or with one or two setae near ventral border, rarely with up to five erect setae along posterior border.

A. araneoides 


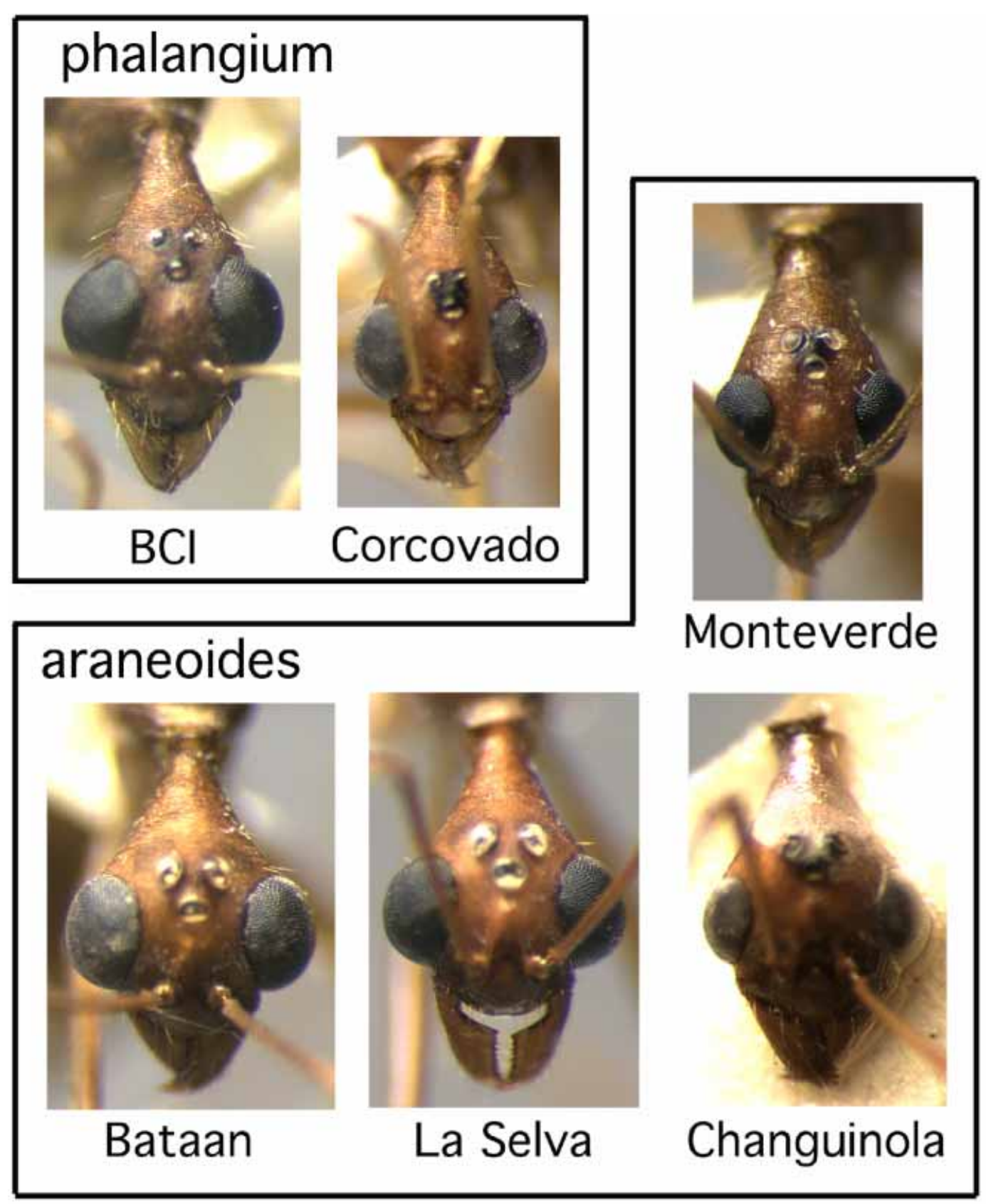

ZOOTAXA

\section{$1 \mathrm{~mm}$}

FIGURE 4. Face view of male, Aphaenogaster phalangium complex. 

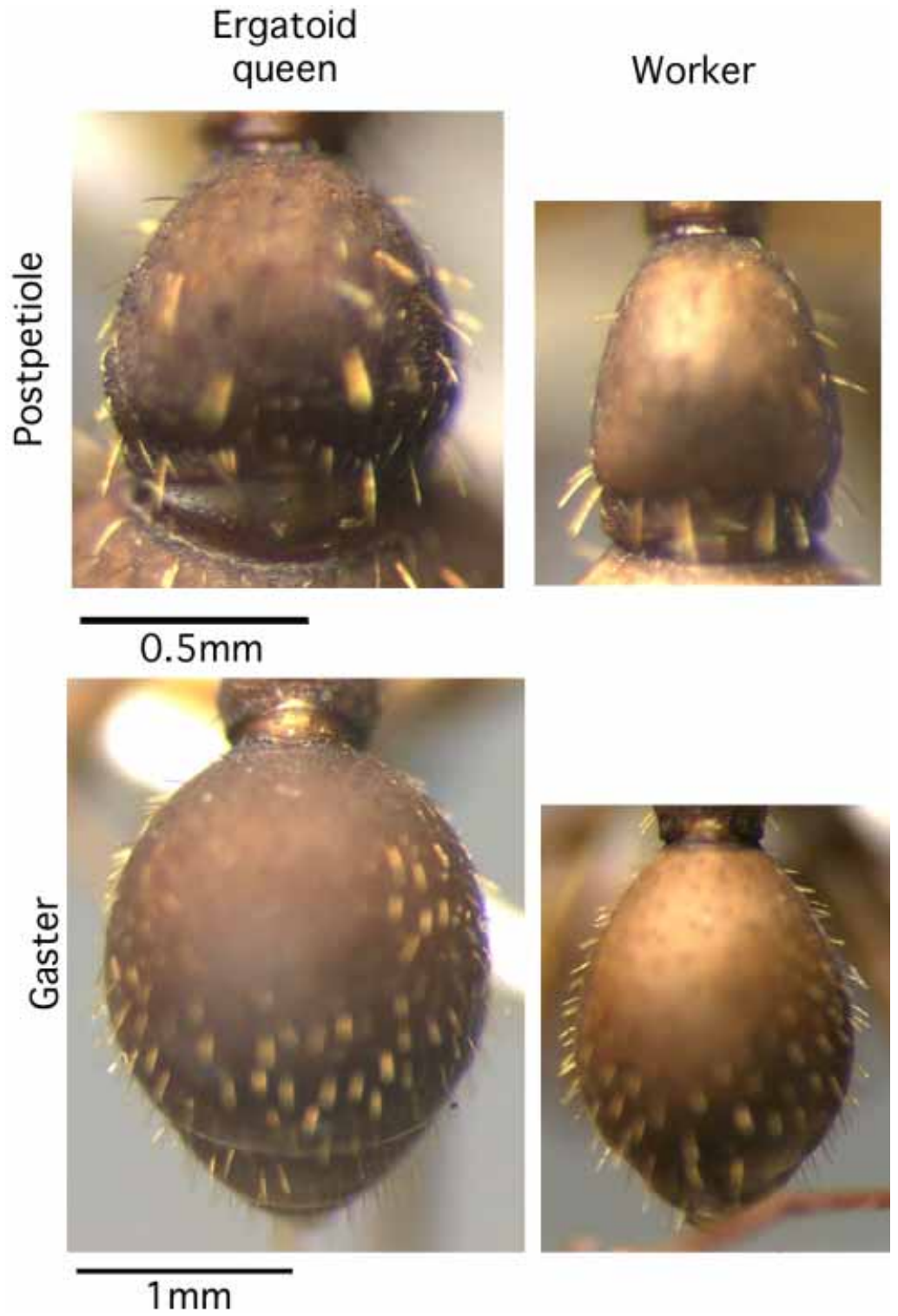

FIGURE 5. Dorsal view of postpetiole and gaster, Aphaenogaster phalangium complex, contrasting ergatoid queen and worker.

\section{Taxonomy}

\section{Aphaenogaster araneoides Emery}

Aphaenogaster araneoides Emery 1890:48, pl. 5, fig. 8. Syntype workers: Costa Rica [labeled Alajuela, assumed mislabeled, true locality Jimenez] (Alfaro) [MCSN] (examined, worker here designated LECTOTYPE). Also described as new by Emery 1894:54. Description of male 
(incorrectly identified as phalangium): Emery 1890:47. Description of male: Borgmeier 1949:206. Combination in Aphaenogaster (Ischnomyrmex): Forel 1899:60; in Stenamma: Forel 1907:4; in Aphaenogaster (Deromyrma): Emery 1915:71.

Aphaenogaster (Ischnomyrmex) phalangium var. brevicollis Forel 1899:59. Syntype worker, male: Panama, Volcan de Chiriquí (Champion). Combination in Aphaenogaster (Deromyrma): Emery 1921:65. NEW SYNONYMY

Emery (1890) described the first two taxa in the complex. Aphaenogaster phalangium was described first, based on a syntype worker and male from "Alajuela, Jimenez." The worker was described as having a shiny fourth abdominal tergite, and the illustration showed somewhat convex neck and a non-tuberculate propodeum. Aphaenogaster araneoides was described from a syntype worker, also from "Alajuela, Jimenez." It was described as having an opaque gaster, and the illustration shows a tapered neck and a tuberculate propodeum. The published locality data for both species, "Alajuela, Jimenez," is a composite of two collecting localities frequented by Anastasio Alfaro, who sent the material to Emery. Alajuela is a city in the Central Valley of Costa Rica, and is the likely source of the phalangium workers. Jimenez is a small town in the Atlantic lowlands very near La Selva Biological Station, and is the likely source of the A. araneoides workers. The senior author examined the syntypes at MCSN in 1990. Under A. araneoides were (1) a pin with one worker, labeled "Alajuela", and a "Typus" label; and (2) a pin with two workers and an "Alajuela" label. Under A. phalangium were (1) a pin with one worker, labeled "Costa Rica, Alfaro", and with a "Typus" label; (2) a pin with two workers and a "Costa Rica, Alfaro" label, (3) a pin with one worker and an "Alajuela, Alf." label; and (4) a pin with a male labeled "Jimenez." The types were examined before the significance of leg pilosity was understood, and the status of this character was not recorded. However, the worker material under A. araneoides had tapered necks, opaque abdominal tergites, and tuberculate propodeums, while the workers under A. phalangium had convex necks, shiny abdominal tergites, and non-tuberculate propodeums. The MCZC has a pin with two workers, labeled "Ischnomyrma phalangium Em, Costa Rica. from Emery." The specimens and the label look like part of the A. phalangium syntype series, and the specimens have pilose femora. We suspect there were labeling errors, and that all the A. phalangium syntype workers were from one collection from Alajuela, and all the A. araneoides syntype workers and the one A. phalangium syntype male were from one collection from Jimenez. We have requested that the MCSN add labels to these specimens with the suggested corrections. For A. araneoides and A. phalangium we have selected the single workers with Emery's "typus" labels as the lectotypes.

Borgmeier's (1949) description of the male was based on two specimens from Hamburg Farm, a site in the Atlantic lowlands of Costa Rica, where A. araneoides is almost certainly the ony species present.

The syntypes of Forel's A. brevicollis come close to bridging the gap between A. araneoides and $A$. phalangium. The workers are quite robust, there is a row of about five setae on the posterior border of the mesepisternum, the pilosity is abundant and coarse 
(approaching the more pilose condition of A. phalangium), and the fourth abdominal tergite is smooth and shining. The pilosity on the hind femur is relatively coarse compared to other A. araneoides and yet is clearly appressed on the dorsal surface and strongly contrasting with all known A. phalangium workers.

\section{Aphaenogaster phalangium Emery}

Aphaenogaster phalangium Emery 1890:47, pl. 5, fig. 6, 7. Syntype worker, male: Costa Rica [worker probably from Alajuela] (Alfaro) [MCSN] (examined, worker here designated LECTOTYPE, male identified as araneoides). Also described as new by Emery 1894:54. Description of larva (as A. araneoides inermis Forel): Wheeler and Wheeler 1953:64. Combination in Aphaenogaster (Ischnomyrmex): Forel 1899:59; in Aphaenogaster (Deromyrma): Emery 1915:71.

Aphaenogaster (Ischnomyrmex) araneoides var. inermis Forel 1899:60. Syntype worker: Costa Rica (Tonduz); Syntype worker, male: Panama, Bugaba (Champion) [MHNG, MCZC] (examined, MHNG Tonduz worker here designated LECTOTYPE). Combination in Aphaenogaster (Deromyrma): Kempf 1972:23. NEW SYNONYMY

Aphaenogaster (Ischnomyrmex) araneoides var. nitidiventris Forel 1912:15. Syntype worker, male: Costa Rica, Cañas Gudas [sic, Cañas Gordas] (Pittier) [MHNG] (examined). Combination in Aphaenogaster (Deromyrma): Kempf 1972:23. NEW SYNONYMY

Aphaenogaster (Deromyrma) araneoides var. canalis Enzmann, J. 1947:149, pl. 8. worker: Panama. NEW SYNONYMY

See under A. araneoides for discussion of A. phalangium lectotype designation.

The A. inermis syntypes that were collected by Tonduz in Costa Rica are identical to material from Corcovado National Park, with matte gaster and strongly constricted neck. The Wheelers' (1953) description of the larva of A. inermis was based on material from Barro Colorado Island in Panama. The A. nitidiventris syntypes were collected in Cañas Gordas, a site on the border with Panama in the Cordillera de Talamanca. They match more recent collections of $A$. phalangium from this area. They have a highly constricted neck, like material from the nearby Pacific lowlands, but the fourth abdominal tergite is sublucid and weakly shagreened. The identity of Enzmann's A. canalis cannot be unambiguously determined from the description or figure, but the description states "The insect is covered with beautiful golden erect hairs, which are longer and more abundant on the vertex and gaster, shorter and sparser on the thorax and legs." The fact that setae were mentioned on the legs suggests A. phalangium. Types were from Chiriqui, Panama, which, if from the lowlands, would be expected to be A. phalangium.

\section{Discussion}

If, as proposed here, there are two species as revealed by the sympatric leg pilosity character, then the abdominal tergite sculpture, head shape, and propodeal tubercle characters 
show discordant clinal variation that crosses species boundaries. Population sampling for molecular markers should be the next step in testing these species definitions. Patterns of parallel or convergent geographic variation among different species are known for other taxa, including the well-known case of parallel mimicry races in Heliconius butterflies (Turner 1981). Ward (1999) discovered a similar phenomenon when clarifying species boundaries among Neivamyrmex army ants (Ecitoninae) in the southwestern United States. Neivamyrmex nigrescens occurs broadly across the southwestern United States and N. californicus occurs in California and Baja California. The two are sympatric in northern California. Neivamyrmex nigrescens shows pronounced geographic variation, with the northwestern populations strongly differentiated from the southeastern populations and convergent on $N$. californicus. Ward discovered that many collections of nigrescens had been misidentified as californicus because of the morphological convergence in the zone of sympatry.

This parallels what we have discovered in the zone of sympatry of A. phalangium and A. araneoides. The causes of these cases of interspecifically correlated geographic variation are unexplored, but two hypotheses are introgression between the two species and convergence due to natural selection. In the first case there may be frequent gene flow among the two species, such that populations that are in contact share genes that determine such traits as abdominal sculpture and neck shape. In this case the meaning of the species boundaries can be questioned. Admittedly the decision to use leg pilosity as the main separatory character was based largely on its discreteness. Specimens could be unambiguously sorted by the character. It could be that leg pilosity has a simple genetic basis and is itself an intraspecific polymorphism showing clinal variation, and independent of clines for other characters such as abdominal sculpture and neck shape. Alternatively the two species may be well separated genetically, but selection has generated parallel changes in both species. Perhaps selection favors smooth abdomens in montane areas and matte abdomens in lowland habitats.

We have demonstrated strongly developed intraspecific geographic variation similar to that seen in Ecitoninae. It is well-known that army ants have wingless queens and that all long-distance gene flow has to occur through males. Queens of the Aphaenogaster phalangium complex are also wingless. The restricted gene flow in lineages with low-vagility queens may contribute to the excessive geographic variation seen in these and other ant lineages.

The nature of biological diversity and the subjectivity of the taxonomic process illustrate the difficulties in obtaining global tallies of species richness. We have taken six names and made them into two. Another taxonomist might recognize each geographic variant of both A. phalangium and A. araneoides as a distinct species. We can imagine a "splitter" generating at least ten taxa with the material we examined. Using this study as a guide, different approaches to mapping biodiversity (O'Hara 1993) could result in global counts of species richness that differ by a factor of five. 
The following curators were very helpful in the loan of specimens and during museum visits: C. Besuchet, D. Burckhardt, B. Merz, and I. Löbl (MHNG), V. Raineri (MCSN), and M. Zumbado (INBio). Phil Ward (U.C. Davis) generously provided distribution data and discussions of character variation. This work has been supported by the National Geographic Society and by National Science Foundation grant DEB-0072702.

\section{Literature cited}

Bolton, B. (1982) Afrotropical species of the myrmicine ant genera Cardiocondyla, Leptothorax, Melissotarsus, Messor and Cataulacus (Formicidae). Bulletin of the British Museum (Natural History). Entomology, 45, 307-370.

Borgmeier, T. (1949) Formigas novas ou pouco conhecidas de Costa Rica e da Argentina (Hymenoptera, Formicidae). Revista Brasileira de Biologia, 9, 201-210.

Emery, C. (1890) Studii sulle formiche della fauna neotropica. Bullettino della Società Entomologica Italiana $22,38-80$.

Emery, C. (1894) Estudios sobre las hormigas de Costa Rica. Anales del Museo Nacional de Costa Rica, 1888-1889, 45-64.

Emery, C. (1915) Definizione del genere Aphaenogaster e partizione di esso in sottogeneri. Parapheidole e Novomessor nn. gg. Rendiconti delle Sessioni della Reale Accademia delle Scienze dell'Istituto di Bologna. Classe di Scienze Fisiche (n.s.), 19, 67-75.

Emery, C. (1921) Hymenoptera. Fam. Formicidae. Subfam. Myrmicinae. [part] Genera Insectorum, 174A, 1-94 + 7 plates.

Enzmann, J. (1947) New forms of Aphaenogaster and Novomessor. Journal of the New York Entomological Society, 55, 147-152.

Forel, A. (1899) Formicidae. [part]. Biologia Centrali-Americana, 3, 57-80.

Forel, A. (1907) Formiciden aus dem Naturhistorischen Museum in Hamburg. II. Teil. Neueingänge seit 1900. Mitteilungen aus dem Naturhistorischen Museum in Hamburg, 24, 1-20.

Forel, A. (1912) Formicides néotropiques. Part IV. 3me sous-famille Myrmicinae Lep. (suite). Mémoires de la Société Entomologique de Belgique, 20, 1-32.

Kempf, W.W. (1972) Catálogo abreviado das formigas da regia o Neotropical. Studia Entomologica, 15, 3-344.

McGlynn, T.P., Hoover, J.R., Jasper, G.S., Kelly, M.S., Polis, A.M., Spangler, C.M., and Watson, B.J. (2002) Resource heterogeneity affects demography of the Costa Rican ant Aphaenogaster araneoides. Journal of Tropical Ecology, 18, 231-244.

McGlynn, T.P., Shotell, M.D. \& Kelly, M.S. (2003) Responding to a variable environment: Home range, foraging behavior, and nest relocation in the Costa Rican rainforest ant Aphaenogaster araneoides. Journal of Insect Behavior, 16, 687-701.

O'Hara, R.J. (1993) Systematic generalization, historical fate, and the species problem. Systematic Biology, 42, 231-246.

Turner, J.R.G. (1981) Adaptation and evolution in Heliconius: a defense of NeoDarwinism. Annual Review of Ecology and Systematics, 12, 99-121.

Ward, P. S. (1999) Deceptive similarity in army ants of the genus Neivamyrmex (Hymenoptera: Formicidae): taxonomy, distribution and biology of $N$. californicus (Mayr) and N. nigrescens (Cresson). Journal of Hymenoptera Research, 8, 74-97.

Wheeler, G.C., Wheeler, J. (1953) The ant larvae of the myrmicine tribe Pheidolini (Hymenoptera, Formicidae). Proceedings of the Entomological Society of Washington, 55, 49-84. 